\title{
Unconventional functions of mitotic kinases in kidney tumorigenesis
}

\author{
Pauline Hascoet, Franck Chesnel, Cathy Le Goff, Xavier Le Goff and \\ Yannick Arlot-Bonnemains* \\ UMR 6290 (IGDR), CNRS, University Rennes-1, Rennes, France
}

Human tumors exhibit a variety of genetic alterations, including point mutations, translocations, gene amplifications and deletions, as well as aneuploid chromosome numbers. For carcinomas, aneuploidy is associated with poor patient outcome for a large variety of tumor types, including breast, colon, and renal cell carcinoma. The Renal cell carcinoma (RCC) is a heterogeneous carcinoma consisting of different histologic types. The clear renal cell carcinoma (ccRCC) is the most common subtype and represents $85 \%$ of the RCC. Central to the biology of the ccRCC is the loss of function of the Von Hippel-Lindau gene, but is also associated with genetic instability that could be caused by abrogation of the cell cycle mitotic spindle checkpoint and may involve the Aurora kinases, which regulate centrosome maturation. Aneuploidy can also result from the loss of cell-cell

OPEN ACCESS

Edited by:

Mar Carmena,

The University of Edinburgh, UK

Reviewed by:

Robert Friis,

University of Berne, Switzerland

Markus A. N. Hartl,

University of Innsbruck, Austria

*Correspondence:

Yannick Arlot-Bonnemains yannick.arlot@univ-rennes1.fr

Specialty section: This article was submitted to Molecular and Cellular Oncology,

a section of the

journal Frontiers in Oncology

Received: 27 August 2015 Accepted: 12 October 2015 Published: 27 October 2015

Citation: Hascoet P, Chesnel F, Le Goff C, Le Goff $X$ and Arlot-Bonnemains $Y$ (2015) Unconventional functions of mitotic kinases in kidney tumorigenesis.

Front. Oncol. 5:241. doi: 10.3389/fonc.2015.00241 adhesion and apical-basal cell polarity that also may be regulated by the mitotic kinases (polo-like kinase 1, casein kinase 2, doublecortin-like kinase 1, and Aurora kinases). In this review, we describe the "non-mitotic" unconventional functions of these kinases in renal tumorigenesis.

Keywords: mitotic kinases, non-mitotic functions, Aurora-A kinase, kidney, tumorigenesis

\section{INTRODUCTION}

Renal cell carcinoma (RCC) represents approximately $3.8 \%$ of adult malignancies and 90-95\% of kidney neoplasms. The most common histological RCC subtype is the clear cell carcinoma (ccRCC), which accounts for $85 \%$ of cases. At least $80 \%$ of ccRCCs have deletions or translocations involving the short-arm of chromosome 3, which contains the von Hippel-Lindau (VHL) gene at 3p25. Clear cell carcinoma shows highly consistent chromosomal aberrations involving loss of the short-arm of chromosome 3, a partial or complete trisomy $5 \mathrm{q}$, and abnormalities of $6 \mathrm{q}, 8 \mathrm{p}, 9 \mathrm{p}, 10 \mathrm{q}, 11 \mathrm{q}, 12 \mathrm{q}$, and $14 \mathrm{q}$. The second most common cytogenetic abnormality associated with ccRCC is a gain of chromosome 5q6; however, very little is known about its effects. Mitotic errors and misregulation of cell-cycle process are considered to be an important characteristic of kidney cancer. Successful cancer therapies depend mainly on the recognition of physiologic targets that are primarily involved in the regulatory mechanism of cell-cycle progression (1). The members of serine/threonine kinases, such as cyclin-dependent kinases, polo-like kinases, and aurora kinases, are the well studied families that coordinate the mitosis sequence (2). Many studies are generally focused on the role of mitotic functions of these kinases and efforts have been put up to use targets for generation of new anticancer drugs (3). However other non-mitotic functions of these kinases have been identified as diverse as control of the resorption of the cilia, the cell differentiation, and the cell polarity control in interphase cells. 


\section{Kidney Cancer and (loss of) Cell Polarity}

Carcinomas are frequently characterized by loss of cell differentiation and excess of cell proliferation. They are also characterized by a loss of cell polarity, which includes polarity complexes and adhesion complexes proteins dysfunction (4-6). Loss of cell polarity induces cancer development by deregulating different signaling pathways (7). Ultimate loss of the epithelial phenotype may contribute to epithelial-to-mesenchymal transition (EMT) and metastasis. Cell polarity is defined as asymmetry in functional organization of the cell. It is required for the formation and maintenance of functional epithelia. Epithelial cells are highly polarized (i.e., asymmetric distribution of lipids, proteins, RNA, organelles) and are tightly connected by specialized intercellular junctions. In epithelia, maintenance of apico-basal (AB) polarity is crucial for preserving epithelial integrity and depends on cell polarity complexes and cell junctions. Cell polarity is mostly driven by complexes composed of adherens junctional complexes (including cadherin and catenin) and tight junctional complexes that contain zonula occludens (ZO) proteins, occludin, claudin, and junctional adhesion molecules (JAM). These cell polarity complexes have antagonistic roles in regulating the specific distribution of key molecules. The Scribble complex (Scrib, Dlg, and Lgl2) is present in the baso-lateral region of the cell and has antagonistic roles with the apical complexes, Par (Par3, Par6, Cdc42, atypical protein kinase $\mathrm{C}$ ) and Crumbs (Crb3, Pals1, and PatJ). Other conserved Par proteins such as Lkb1 (Par4) and the Parl kinase regulate cell polarity (8).

In the kidney, the epithelium is a simple tube-based structure with the apical membrane facing the lumen whereas the basolateral membrane interacts with the matrix. In kidney tubes, as well as for podocytes, the establishment and maintenance of the epithelium require the presence of the Par, Crumbs and Scribble complexes (9). AB polarization of the renal epithelium is crucial for the appropriate function of the normal kidney in waste products and extra water removal and electrolyte balance. Disruption of cell polarity in kidney is involved in renal pathologies such as acute renal failure, which affects tight junction function (10) and polycystic kidney disease (PKD) in which polarity factors are frequently mislocalized (11). Polarity complexes expression and functions are frequently deregulated in cancer. Implication of polarity complex proteins as oncogene or tumor suppressor in tumorigenesis depends on the kind of alteration of their expression. It is also dependent on the origin of the epithelium (12). For instance, Par3 expression is lost in glioblastoma, esophageal squamous carcinoma, breast, lung, head, and neck cancers (13-16) but is overexpressed in some RCC (17) or in some severe hepatocellular carcinoma (18). Thus both up- and down-regulation of critical cell polarity proteins may be associated with tumorigenesis. Consistent with this notion, expression and functional studies in different skin tumors showed either oncogenic or tumor-suppressive functions of Par3 depending on the cellular context (19).

It has been widely admitted that ccRCC originates from proximal epithelial tubular cells. This is based on specific cellular marker expression $(20,21)$ or genetic expression pattern (22). However, epithelial cells of other nephron segments may also promote some cases of ccRCC. Interestingly, based on studies in VHL patients, ccRCC may also arise from VHL-null epithelial cells, which show markers of dedifferentiation (23). In colon adenocarcinoma, it has been reported that both expression levels and subcellular localization of the Scribble polarity complex component Dlg could be deregulated. However, in ccRCC, Dlg expression level is unaltered compared to normal kidney epithelial cells, but the protein is mislocalized in a granular distribution in clear cells. It was proposed that altered localization of Dlg may contribute to cell transformation and promotes high migration ability (24).

In ccRCC, the polarity protein Par3 overexpression is correlated with a poor prognosis (17). The localization of Par3 at both the plasma membrane and in the cytoplasm was associated with worse clinical factors in a cohort of 101 ccRCC patients (25). Furthermore, Dugay et al. showed that Par3 up-regulation was associated with cytoskeleton defects and increased cell migration capacity. This was restored by Par3 down-regulation whereas other Par complex component expression levels remained unchanged (17). Crumbs3 (Crb3) is involved in establishment of AB polarity and formation of tight junctions. Knock-out mice showed strong defects in epithelial $\mathrm{AB}$ polarity and thus in establishment and maintenance of epithelial cells. In contrast to Par3, loss of Crb3 expression induces tumorigenesis in kidney cells. This effect was associated with several characteristics of cell polarity disruption. This phenotype was reversed upon restoration of Crb3 expression $(26,27)$. Accordingly, loss of Crb3 is associated with a shorter overall survival in ccRCC (28). Altogether, polarity factors mislocalization and/or their deregulated expression are associated with tumor progression. This may be due to altered epithelia organization involving cell-cell contact disruption, a higher ability to transform phenotype (EMT) and for cell migration, and/or increased cell proliferation signaling.

\section{Kidney Cancer and EMT}

The EMT is known for more than a decade to participate in tumor progression and metastasis formation in many carcinomas. This process by which epithelial cells acquire a mesenchymal phenotype starts with loss of cell-cell adhesion and polarity and leads to increased cell motility and invasion. At the molecular level, EMT is characterized by the alteration of some gene expression profiles resulting in down-regulation of epithelial markers (such as E-cadherin, ZO-1, and cytokeratins), and up-regulation of mesenchymal markers, such as vimentin (29).

The implication of EMT in clear cell renal cell carcinoma (ccRCC) progression and invasiveness has been established within the last 5 years, especially when investigators were searching for new biomarkers associated with clinical outcome. While comparing mRNA levels of 46 EMT-related genes between RCC and healthy kidney samples, Chen and colleagues showed that low vimentin, CXCR4, fibronectin, and TWIST1 transcript levels are correlated with a better outcome whereas overexpressed vimentin and CXCR4 constitute independent markers for poor prognosis in RCC patients (30). Likewise, using an 
immunohistochemical approach on a cohort of 122 RCC patients, protein expression levels of vimentin, TWIST, E-cadherin, and clusterin were identified as predictors of disease recurrence (31). Overexpression of zinc-finger transcription factors SNAI1/Snail or ZEB2/SIP1, well-known EMT inducers acting as repressors of E-cadherin transcription, has also been associated with poor prognosis in RCC patients $(32,33)$. It could result at least in part from the loss or a decreased expression of NDRG2 and FOXO3a observed in high grade or metastatic RCC tumors, respectively $(34,35)$. Several mechanisms have been proposed to explain how EMT is induced and/or sustained during kidney tumorigenesis.

As a consequence of the functional inactivation of VHL very often observed in ccRCC, accumulation of Hypoxia-induced transcription factors HIF1 and/or $2 \alpha$ leads to the transcriptional activation of many HIF target genes. Among them, erythropoietin (EPO) may stimulate EMT in RCC via the PI3K/Akt/mTOR pathway (36) in agreement with the observations that the mTOR inhibitor Everolimus was able to slow down RCC tumor growth and to reverse EMT phenotype in a mouse xenograft model (37). At least two proinflammatory cytokines, tumor necrosis factor alpha (TNF $\alpha)$ and interleukin 15 (IL-15), have been reported to play a role in EMT induction in RCC. Serum levels of TNF $\alpha$ are significantly increased in RCC patients as well as secretion by tumor cells and it was demonstrated that TNF $\alpha$ promotes EMT in RCC by decreasing E-cadherin expression and increasing vimentin expression and MMP9 activity $(38,39)$. This TNF $\alpha$ effect is mediated through the inhibition of GSK3 $\beta$ in a NFkBindependent manner $(39,40)$. In contrast, IL-15 production is not altered in RCC but the IL-15 signaling pathway is profoundly modified because of the expression of a particular transmembrane IL-15 form and the defective expression of CD132 ( $\gamma \mathrm{c}$ chain of the IL-2 receptor family) and JAK3 (41), which both favor EMT through down-regulation of E-cadherin expression (42).

\section{Kidney Cancer and Angiogenesis}

To proliferate, cancer cells require a continuous supply of nutrients and oxygen. This supply is function of the distance between tumor vessels and cancer cells, leading to intratumoral hypoxia heterogeneity (43). To overcome this phenomenon, angiogenesis is up-regulated in most cancers, due to an overproduction of angiogenic stimulators and the consequent unbalanced proportion of activators (such as VEGF, MMPs, FGF, HGF...) and inhibitors (such as thrombospondins, endostatin, angiostatin...) in favor of the hyperactive tumor vasculature development (44). Therefore, tumor vessels are disorganized, tortuous, and mal-shaped with fewer mural pericytes (45). Moreover, proliferating cancer cells can also exert a pressure on intratumoral blood and lymphatic vessels (46) leading to an impaired blood perfusion. These vascular abnormalities lead to a hypoxic, acidic, and hypertensive tumor microenvironment. Adaptation to hypoxia at the cellular level is mainly regulated by the Hypoxia Inducible Factors (HIFs).

In ccRCC, the HIF system is up-regulated both by microenvironmental hypoxia and a genetic event, the VHL inactivation, that lead to HIF- $\alpha$ stability. Indeed, the VHL gene is deleted, mutated or hypermethylated in $\sim 90 \%$ of the cases, leading to the absenceor to the expression of a non-functionalpVHLprotein(47).
HIFs, the main targets of pVHL, are transcription factors responsible for numerous hypoxia responses by promoting expression of genes involved in the cellular adaptation to hypoxia. In normoxia, the oxygen-dependent prolyl hydroxylated domain containing proteins (PHDs) specifically hydroxylate HIF- $\alpha$ in its N-terminal transactivation domain (NTAD) $(48,49)$, allowing its interaction with pVHL, the substrate recognition subunit of an E3 ubiquitin ligase complex, and its subsequent degradation by the $26 \mathrm{~S}$ proteasome (50). HIF- $\alpha$ can also be hydroxylated in an oxygen-dependent manner on its C-terminal transactivation domain (CTAD) by the Factor Inhibiting HIF (FIH-1). This hydroxylation prevents the recruitment of the transcriptional co-activators CBP and p300. Thus, under low oxygen conditions or in absence of a functional pVHL, HIF- $\alpha$ is stabilized and can dimerize with the stable HIF- $\beta$, and this heterodimer transcriptionally activates up to 200 genes involved in cell growth, glucose metabolism, angiogenesis, apoptosis, $\mathrm{pH}$ regulation... One of the most described targets of HIFs is the vascular endothelial growth factor (VEGF). It is overexpressed at the mRNA and protein levels in ccRCC compared to normal kidney tissues $(51,52)$. Endothelial cells but also RCC cells express the VEGF Receptor (VEGFR-2), inducing increased tumor angiogenesis. VEGF and its receptor constituted the main targets for metastatic RCC treatments such as Sunitinib, Sorafenib, Pazopanib, and Bevacizumab (53-55). However, most of the ccRCC patients develop resistance to these VEGF inhibitors. mTOR inhibitors (Temsirolimus and Everolimus) were also used for RCC treatment by acting downstream of the VEGF receptor through HIF down-regulation since mTORC1 drives HIF-1 $\alpha$ synthesis (56).

The HIF $\alpha$ family is composed of three different members (HIF-1 $\alpha$, HIF- $2 \alpha$, and HIF-3 $\alpha$ ). HIF- $1 \alpha$ is ubiquitously expressed whereas HIF-2 $\alpha$ expression is more restricted, but both isoforms are co-expressed in numerous cell types. HIF- $1 \alpha$ and HIF- $2 \alpha$ have common and also unique targets and are thought to have overlapping functions, but also divergent outcomes in tumorigenesis. In fact, HIF- $1 \alpha$ and HIF- $2 \alpha$ were first considered as essential for ccRCC progression but several studies tend toward an oncogenic role for HIF- $2 \alpha$ in ccRCC and a tumor suppressor function for HIF- $1 \alpha(23,57,58)$. Moreover, most of the $\mathrm{VHL}^{-/-}$ccRCC cell lines do not express HIF- $1 \alpha$ whereas they all express HIF-2 $\alpha$, suggesting a selective pressure to maintain HIF- $2 \alpha$ expression.

\section{Kidney Cancer and Ciliogenesis}

Kidney epithelial cells have developed primary cilia that extend into the tubular lumen. This includes cells in the parietal layer of Bowman's capsule, proximal tubules, the loop of Henle, and the collecting duct. Cilia are present on almost all cells lining the nephron, with the exception of intercalated cells (59).

In the kidney, the cilium serves as a flow sensor in the kidney tubules lumen, with flow-induced ciliary bending causing a transient increase in intracellular calcium (60). Polycystins (PC) 1 and 2, gene products of PKD1 and PKD2, are large multi-pass transmembrane proteins of the transporter receptor potential channel (TRPC) family of calcium transporters. Mutations of PKD1 and PKD2 induce cyst formation in the kidney, and cyst 
formation in part arises because of derestricted cell proliferation. Thus PC1 and PC2 at least indirectly participate in cell-cycle control. Signaling downstream of PC1 and PC2 is quite complex. In normal cells, these proteins negatively regulate the cAMP and Raf-MEK-ERK signaling pathways (61), both of which being hyper activated in renal epithelial cysts (62).

The primary cilium of the kidney epithelium mediates sensation of mechanical signals produced by apical fluid shear stress and its transduction into an intracellular $\mathrm{Ca}^{2+}$ signaling response $(63,64)$. In cell culture, deflection of the cilia axoneme initiates a transient increase in the level of intracellular $\mathrm{Ca}^{2+}$ resulting from $\mathrm{Ca}^{2+}$ entry through a channel, possibly PC1 and PC2, located in the cilium. This is supported by the fact that the $\mathrm{Ca}^{2+}$ influx generated by fluid flow is abolished in cell lines lacking polycystin-1 (65) and by the loss of fluid flow-mediated calcium signaling in the embryo.

Accordingly, defects in assembly or function of primary cilia lead to a plethora of developmental disorders and pathological conditions known as ciliopathies (66). Cystic kidney disorders are one of the leading causes of end-stage renal disease. Several proteins implicated in the pathogenesis of PKD localize to cilia. In the growth of the renal normal tubule, the mitotic spindle of dividing cells aligns along the axis of the nephron. However, in cells with mutations within Pkhd1 (encoding fibrocystin) as well as $H n f-1$ genes, the spindle fails to correctly orient inducing abnormal cell division (67).

An important feature of ciliary signaling is the continuous interaction with regulatory signaling molecules at the ciliary base, i.e., the centrosomal region, which may coordinate the crosstalk between separate ciliary signaling pathways to activate specific cellular targets and gene arrays for specified cellular or tissue responses $(67,68)$.

The VHL disease is caused by germline mutation in the $v h l$ tumor suppressor gene. One of the major clinical manifestations of the disease includes kidney tumor. Around $80 \%$ of the VHL patients developed renal cysts. pVHL localized to the cilia. Ectopic expression of VHL gene in renal clear cell carcinoma cell lines restored cilia formation, implying that pVHL might directly support ciliogenesis (69). Inactivation of VHL and GSK-3b was required to allow loss of cilia based on cooperative function of these proteins in ciliary maintenance. pVHL also regulates microtubule orientation during ciliogenesis and interacts with the Par3-Par6-atypical PKC complex, which supports ciliogenesis (70). Moreover, pVHL associates with kinesin 2, allowing pVHL to influence microtubule dynamics in support of cilia $(71,72)$.

\section{Genetic Instability and Kidney Cancer}

A large proportion of tumors are aneuploid and this abnormal number of chromosomes is thought to contribute to tumorigenesis. It is associated with poor prognosis, multidrug resistance, and increased capacity to metastasis. Genomic instability may be the result of several mitotic defects (73-75).

During mitosis, the formation of a bipolar mitotic spindle is essential for proper chromosome segregation. The chromosome segregation mediated by the anaphase-promoting complex/ cyclosome (APC/C) is controlled by the spindle assembly checkpoint (SAC). This checkpoint arrests cell-cycle progression by modulating the activity of the mitotic kinase CDK1 until all chromosomes are properly attached to the mitotic spindle (76, 77). The chromosomal passenger complex (CPC), composed of Aurora-B, INCENP, Borealin, and Survivin, plays also a critical role at different stages of mitosis and cytokinesis by recruiting condensin complex in mitotic entry $(78,79)$ and by activating SAC in metaphase if chromosomes are not properly attached to the spindle. Its relocalisation from anaphase chromosomes to cell equator promotes mitotic exit and cytokinesis (80). Hence, deregulated CDK1 activation, weakened mitotic checkpoint, defective chromatid cohesion or condensation, may contribute to genomic instability. Indeed several alterations in mitotic genes have been reported in human cancer with chromosome instability (81). The duplication and maturation of centrosome is a critical step for the formation of a bipolar mitotic spindle. Thus, centrosome amplification, enrichment for centrosome components [such as CDK1, NEK2, Aurora-A, Aurora-B, or Polo-like kinase 1 (Plk1)] or merotelic attachment of chromosomes to the mitotic spindle may promote abnormal cell division and aneuploidy (77, 82, 83).

A recent study on VHL showed that this protein is a controller of mitotic fidelity in vivo (84). VHL is localized to the mitotic spindle. The loss of function of pVHL in cellulo and in vivo provokes spindle misorientation as a result of unstable astral MT and chromosome instability due to SAC impairment $(85,86)$. This aneuploidy phenotype in VHL-deficient renal carcinoma cell lines is suppressed by ectopic expression of $\mathrm{Mad} 2$, a regulator of APC/C (85) or inhibition of miR-28-5p, a key regulator of Mad2 protein translation upregulated in a variety of cancers $(84,87)$. This result suggests that low level of Mad2 is linked to chromosomal instability (CIN) in VHL-associated kidney cancers (86).

It has been observed that the VHL loss of function is not sufficient to explain tumor formation in kidney. Recently, Albers et al. have shown that secondary genetic alterations of p53 can cooperate with loss of pVHL to induce tumors in mice (88). Detailed cytogenetic analysis of tumor at different stages and gene expression analysis are necessary to understand tumor development and the molecular basis that contribute to aneuploidy.

\section{Non-Mitotic Roles of Mitotic Kinases in Kidney Cancer Polo-Like Kinase 1}

Polo-like kinase 1 is the best characterized member of the Plks family (89). This serine/threonine kinase is known to regulate multiple stages of mitosis. Its expression is cell-cycle regulated since it increases from late $\mathrm{S}$ phase to mitosis, and its degradation mediated by APC/C starts in late mitosis. In interphase, Plk1 is expressed in the cytoplasm and at the centrosomes whereas in mitosis, it localizes to the centrosomes in prophase, then becomes enriched at kinetochores during prometaphase and metaphase, and in late mitosis a fraction of Plk1 is found at the spindle midzone (90). Plk1 is not only involved in the assembly of a bipolar spindle, centrosomes duplication and maturation, DNA replication, and DNA damage checkpoint, but also in the control of the G2/M transition. Several studies demonstrate its role not only in sister chromatid dissociation but also in mitotic exit and cytokinesis [reviewed in Ref. $(91,92)]$. 
Since Plk1 is a key regulator of the cell division, it evidently appeared as an interesting target for anti-mitotic chemotherapeutic drugs (93). Small-molecule inhibitors of Plk1 activity have been developed. Several phase II trials were performed in solid tumors using for instance BI2536, a Plk1 inhibitor, but it exhibited a limited anti-tumoral activity, suggesting that more favorable pharmacological derivates are required (94). Despite these non-conclusive trials, Plk1 remains a promising target since it is overexpressed in a number of human tumors: esophageal squamous cell carcinoma (95), hepatocellular carcinoma (96), bladder carcinoma (97), thyroid carcinoma $(98,99)$, colorectal cancer (100), pancreatic cancer (101), prostate cancer (102), melanoma (103), breast cancer (104), and ovarian cancer (105). Its overexpression is often correlated with tumor grade, sometimes with metastatic disease (103), and proposed as prognosis factor. Interestingly, a gene expression profiling performed on ccRCC patient primary tumors identified Plk1 as significantly correlated with disease malignancy (106). Plk1 is overexpressed at the mRNA and protein level in RCC patient tissues (107) and this overexpression is correlated with the tumor grade and metastases. Moreover, Plk1 knock-down by siRNA strategy or small-molecule inhibitor decreased ccRCC cell proliferation in vitro by G2/M blockade (106) and invasion properties (107). To date, no clinical trial was performed using Plk1 inhibitors alone or in combination with other drugs in RCC patients. Intratumoral injections of Plk1 inhibitor in ccRCC xenograft nude mice induced a tumor volume decrease indicating that a sustained inhibition of Plk1 function may inhibit ccRCC tumor growth in vivo (106). Intriguingly, another in vivo study reported that a liposomal anti-Plk1 siRNA delivery system failed to inhibit tumor growth in a mouse xenograft RCC model (108).

Non-mitotic functions were recently attributed to Plk1, including a role in cilia disassembly. Indeed, an overexpression of Plk1 dramatically reduces the length and the percentage of primary cilia whereas the depletion of Plk1 or the inhibition of its kinase activity induces a delay in cilia disassembly (109). Even if Plk1 is not required for proper ciliogenesis (110), Lee and colleagues identified a new primary cilia disassembly pathway mediated by Wnt5a, CK1€, Dvl2, and Plk1 (111). Under growth stimulation, the non-canonical ligand of the Wnt pathway, Wnt5a, enhances the Plk1 bound to Dvl-2, formerly phosphorylated by CK1є. This interaction stabilizes HEF1 and the HEF1/AurA complex, leading to the HEF1/AurA dependent primary cilia disassembly. Another study has demonstrated that Plk1 is recruited to the pericentriolar matrix by PCM1, a centriolar satellite protein (109). This interaction requires prior phosphorylation of PCM1 by CDK1. Then, Plk1 is activated by Aurora-A and promotes primary cilia disassembly. Moreover, KIF2A, a member of the kinesin-13 protein family with only an ATP-dependent microtubule depolymerization activity, is phosphorylated by Plk1 at the level of subdistal appendages of the mother centriole (112). This event enhances MT depolymerization to disassemble primary cilia. KIF24, another kinesin-13 protein, was previously described to suppress inappropriate ciliogenesis in proliferating cells by stabilizing CP110 (113). In quiescent cells, KIF2A and KIF24 are both ubiquitinated by APC/C, which may prevent a premature initiation of cilia disassembly (112). Interestingly, this Plk1-KIF2A pathway was found constitutively active and described as involved in defective ciliogenesis in a ciliopathy named premature chromatid separation (PCS) syndrome (114). Of note, Plk1 was also associated to another ciliopathy, the nephronophthisis (NPH), a cystic kidney disease. Indeed, Plk1 colocalizes at the transition zone of the cilia with nephrocystin 1 (NPHP1), a scaffold protein of the NPH protein complex frequently mutated in NPH patients. Plk1 phosphorylates NPHP1, leading to cilia disassembly (115). The function of this phosphorylation and its link with cilia disassembly remain to be determined, but this study highlighted another signaling role for Plk1 in cilia disassembly at the transition zone. Further investigations are needed to study whether the non-mitotic function of Plk1 in cilia disassembly is involved in ccRCC development since this pathology is strikingly linked to cystic lesions and thus cilia defects.

\section{Casein Kinase 2}

Casein kinase 2 (CK2) is a ubiquitously expressed and much conserved serine/threonine protein kinase, which is composed of two catalytic $\alpha$-(or $\left.\alpha^{\prime}-\right)$ and two regulatory $\beta$-subunits. This constitutively active kinase is involved in cell proliferation and survival; it exerts pleiotropic effects throughout cell-cycle progression and notably during mitosis, when CK2 $\alpha$ is transiently hyperphosphorylated (116). During the G2-M transition, it first plays a role in chromatin condensation by phosphorylating DNA topoisomerase $2 \alpha$ (117). It also participates in the activation of $\mathrm{M}$-phase promoting factor, CDK1-cyclin B, both by phosphorylating/activating the phosphatase CDC25B and by facilitating PLK1-mediated Wee1 inhibition $(118,119)$. CK2 is then located on the mitotic apparatus in a Pin-1-dependent manner where it shares with Plk1 the microtubule plus-end-tracking protein CLIP170 as a substrate, the phosphorylation of which regulates the timely microtubulekinetochore attachment and contributes to proper chromosome alignment at metaphase (120). Together with the Aurora-B mitotic kinase, CK2 is later involved in spindle elongation and chromosome segregation during anaphase in yeast and interestingly, loss of CK2 activity has been shown to activate SAC (121).

Casein kinase 2 has been shown to be overexpressed, and its activity increased, in ccRCC compared to healthy kidney (122), as reported in many other cancer types. Such deregulation of CK2 activity during mitosis may be sufficient to cause mitotic chromosome instability and the ensuing aneuploidy that have been established to promote tumorigenesis. There is however evidence from several reports regarding solid tumors to suggest that overexpression of CK2 could also influence kidney tumor development through non-mitotic mechanisms. First, CK2 could exacerbate angiogenesis in hypoxic renal tumors since the potent and selective small molecule CK2 inhibitor CX-4945 (also called silmitasertib) has been shown to exert anti-tumor activity through inhibition of angiogenesis in breast cancer (123). This proangiogenic effect of CK2 has been recently discussed [see for review in Ref. (124)]; it is likely the result of several possible actions of the kinase in the signaling cascade leading to hypoxia-mediated transcription of HIF target genes (see Figure 1 for details).

Proangiogenic effect of overexpressed CK2 could additionally be mediated by local overproduction, by tumoral and peripheral blood mononuclear cells, of prostaglandin E2 (PGE2), the most predominant and biologically active eicosanoid produced 


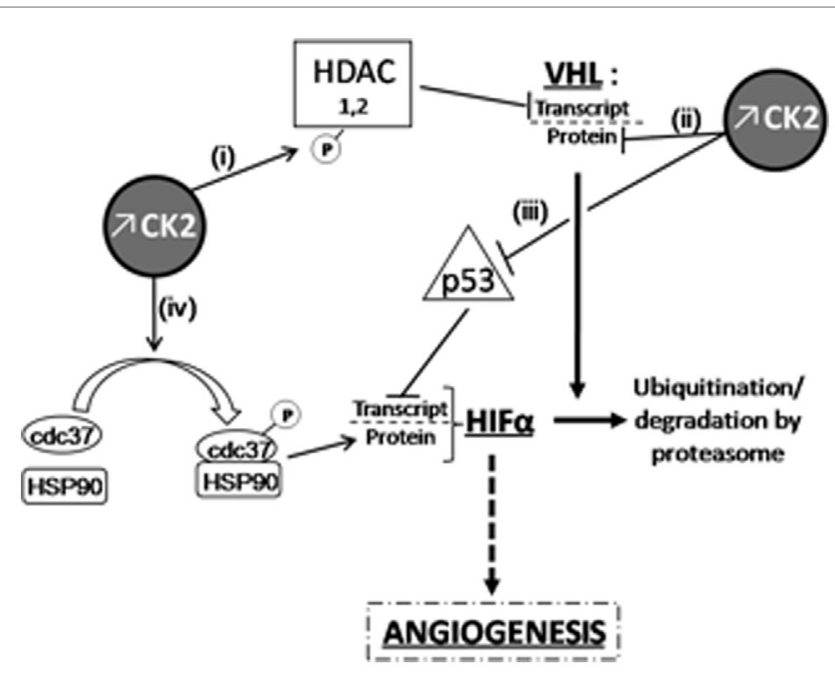

FIGURE 1 | Overexpressed CK2 induces HIF $\alpha$ accumulation through VHL-dependent or independent mechanisms. CK2 can down-regulate VHL expression at the transcriptional level (i) by phosphorylating HDACs (125) as well as at post-translational level and (ii) by destabilizing phosphorylation in the $\mathrm{NH}_{2}$-terminal acidic domain of $\mathrm{VHL}$ (126). In the latter case, $\mathrm{CK} 2$-induced destabilization of $\mathrm{VHL}$ also results in $\mathrm{p} 53$ inactivation, which can no longer inhibit HIF $\alpha$ transcription (iii); $(126,127)$. Finally, (iv) cdc37 phosphorylation by CK2 allows HSP90/cdc37 dimer formation and the subsequent interaction of this complex with $\mathrm{HIF-1} \alpha$, which is essential for its cellular stability $(128,129)$.

by cyclooxygenase 2 (COX-2); this enzyme is indeed often upregulated in ccRCC, likely through a CK2-induced Wnt/ $\beta$ catenin pathway and its expression is correlated with prognosis [see for review in Ref. (130)].

Besides, overexpression of COX2 is also associated with tumor cell migration and invasion as well as the PGE2 receptor EP4, the expression of which is strongly correlated with ccRCC tumor stage and aggressiveness and the presence of metastases (130) but there is to date no such available data connecting CK2 expression levels and tumor progression. A few recent studies on other solid tumors (lung and colon) nevertheless suggest that CK2 could also be involved in the EMT: CK2 $\alpha$ is overexpressed in colorectal cancer compared to adenoma or healthy colorectal tissue and its silencing by RNA interference, while slowing down tumor cell proliferation also inhibited cell motility and invasion. At the molecular level, CK2 $\alpha$ knock-down was able to reverse the EMT process by decreasing vimentin expression and upregulating E-cadherin (131). Similar observations were reported in A549 lung adenocarcinoma cells in which CK2 inhibition with CX-4945 strongly decreased cell migration and invasion at least through the attenuation of PI3K/AKT and ERK signaling pathways and blocked TGF- $\beta$-induced EMT $(132,133)$. Further investigation is worth pursuing in ccRCC to reveal such implication of overexpressed CK2 in EMT process and in the regulation of tumoral cell migration and invasion.

\section{Doublecortin-Like Kinase 1}

Doublecortin-Like Kinase 1 (DCLK1) was first isolated in Caenorhabditis elegans as the product of the zyg- 8 gene. Zyg- 8 loss-of-function alleles were isolated in a visual screen for mutants deficient in spindle positioning in the C. elegans one-cell stage embryo. The phenotype was due to shortening of astral MT during anaphase leading to a defect in spindle-cortex interaction. ZYG-8 is a microtubule-associated protein (MAP), which promotes MT stabilization. ZYG-8 encodes a protein kinase that harbors a catalytic kinase domain and a domain similar to human Doublecortin (DCX), a MAP, which stimulates MT polymerization. Both domains are required for its function in $C$. elegans where ZYG-8 localizes to MT. ZYG-8 kinase also binds to MT in vitro and in vivo through its DCX domain in mammalian cells. ZYG-8 function is required to maintain spindle architecture during anaphase and influences spindle positioning and thus the proper progression of mitosis (134). Later, it was shown that DCLK is a MT-associated kinase, which regulates spindle formation in neuronal cells. DCLK overexpression induced large monopolar spindles and a prometaphase arrest in mitotic neuronal cells. On the other hand, DCLK silencing perturbed mitotic spindle organization with shorter and thinner MT also promoting prometaphase arrest (135). Thus, in metazoans, DCLK1 has a conserved mitotic function in regulating spindle formation.

Doublecortin-Like Kinase 1 was identified as a marker of tumor stem cells (TSC) for instance in pancreatic and colorectal cancers (136) and is upregulated in many other solid tumors. It has been recently suggested that DCLK1 may constitute a potential relevant diagnostic and prognostic marker of circulating cancer cells [e.g., pancreatic adenocarcinoma (137)]. RCC cells share many characteristics with TSC, including an EMT phenotype. Interestingly, DCLK1 is epigenetically dysregulated and overexpressed in more than $90 \%$ of RCC tumors. Increased expression of DCLK1 correlates with stages II and III tumors. Expression of DCLK1 was correlated with the EMT phenotype in RCC. Consistently, silencing of DCLK1 in renal Caki-2 cell line promoted EMT-specific transcription factors down-regulation (SNAI1/SNAI2, TWIST1, and ZEB1) and reduced migration and invasion capacities. A decreased adhesive phenotype was also observed and correlated with a decrease in the expression of the focal adhesion regulator PTK2 (FAK). DCLK1 may regulate migration and invasion through the maintenance of focal adhesion (138). Whether MT and F-actin binding of DCLK1 is involved in its adhesion function remains to be investigated. Interestingly, it has been recently suggested that phosphorylation of FAK by the sphingosine kinase-1 may promote renal cell invasion (139). Thus DCLK1 may contribute to the metastatic process and targeting this kinase should be considered as part of an anti-cancer therapy (140).

\section{Aurora-A Kinase}

Aurora-A is a centrosomally localized cell-cycle regulatory serine/threonine kinase that activates the cyclin B1-Cdk1 mitotic kinase and coordinates formation of a bipolar spindle and nuclear envelope breakdown in $\mathrm{M}$ phase. The serine/threonine kinase Aurora-A localizes on duplicated centrosomes from the end of $S$ phase to the beginning of the following G1 and is essential for mitotic entry, centrosome duplication, spindle formation, chromosome segregation, and cytokinesis (141). Aurora-A is activated by phosphorylation from the end of S phase until the next G1 when 
the kinase is ubiquitinated and degraded by the proteasome in a Cdh1-dependent manner $(142,143)$. The major roles of Aurora-A kinase have been widely described in the centrosome separation and spindle formation. Aurora-A is activated mainly by Ajuba (144); TPX2, Bora, as well as protein phosphatase inhibitor-2 $(145,146)$ and the focal scaffolding proteins HEF1 and NEDD9 (72). Phosphorylation of Aurora-A on T288 residue within the activation loop of the catalytic domain results in the activation of the protein. Aurora-A has multiple other phosphorylation sites modulating its mitotic and non-mitotic activities (S51, S53/S54, S66/S67, S89, S98, and S342 residues) (147). The relevance of the different phosphorylation sites is not actually well known.

The human Aurora- $A$ gene resides at chromosome 20q13.2, a region that is commonly amplified in primary breast tumors, colorectal cancers, and other cancer cell lines, including breast, ovarian, colon, prostate, neuroblastoma, and cervical cell lines (148). Aurora-A abnormalities have been reported in a variety of malignant tumors correlated with an Aurora-A gene amplification or upregulation of Aurora-A expression in tumor tissues compared with normal tissues (149). Controversial studies suggested that Aurora-A abnormalities were positively correlated with aggressive tumor behavior invasion, and nodal metastasis, but some studies showed no correlation or an inverse correlation (150). The oncogenic effects of Aurora-A was attributed to its interaction with several important cellular proteins, including protein phosphatase 1, target protein for xklp2, HEF1, p53, CENP-A, Ajuba, and transforming acidic coiled-coil (141).

Even though the expression of the kinase from $S$ to $M$ phase and the localization of Aurora-A onto the centrosome and the spindle pole have been widely described, it becomes more and more evident that Aurora-A is present in all phases of the cell cycle and might fully participate in other functions that mitotic ones. Several recent studies have described non-mitotic functions of Aurora-A in cellular calcium signaling, cilia resorption or cytoskeleton organization. The presence of diffuse Aurora-A staining in the cytosol, the Golgi and perinuclear region hinted that it had a possible role unrelated to mitosis (151).

Previous studies have shown a potential role of Aurora-A in metastasis and that Aurora-A ectopic expression induced a robust increase in cell migration through its effect on tubulin polymerization $(147,152)$. The mechanism by which the kinase is involved in the process of mobility, migration, and invasion is not completely defined but it has been suggested a role of RAS, AKT, RALa, and MAPKs (153). Aurora-A has been shown to be implicated in cell migration along with SRC and FAK and, unexpectedly, is regulated by a lipase, phospholipase D2 (PLD2). Phosphatidic acid is able to bind and activate Aurora-A causing rapid tubulin polymerization and leading to an enhanced cell migration (154). The action of Aurora-A on cell mobility has also been investigated through a group of proteins involved in the focal adhesion as NEDD9, SRC and FAK. The effect of Aurora-A on cell migration is augmented in the presence of SRC and, in return, Aurora-A also activates FAK. Cell migration is also physically mediated by actin cytoskeleton and is initiated by the protrusion of the cell membrane (155). Overexpression of Aurora-A regulates actin reorganization, leading to free barbed end formation. Cofilin has emerged as an essential player for the localized formation of the barbed ends, which act as sites for new local actin polymerization, thus determining the direction of cell protrusion and movement (156). A significant correlation between Aurora-A expression and cofilin dephosphorylation was described in the immunohistochemical analysis of clinical breast cancer specimens, supporting a novel signaling mechanism by which Aurora-A indirectly induced cofilin dephosphorylation and actin reorganization, thus promoting mammary cell movement and breast cancer metastasis (157). Most importantly, Aurora-A was demonstrated to enhance EMT and invasiveness via activation of MAPK signaling pathway. A novel oncogenic crosstalk between Raf/MAPK and Aurora-A signaling pathways has been established in the development of EMT, stemness, and tumor progression in ER $\alpha$ breast cancer cells. The constitutive activation of MAPK signaling pathway during tumor growth leads to the stabilization and accumulation of Aurora-A which induces the EMT (158). Aurora-A inhibition by VX-680 induced a significant suppression of cell invasion ability, as well as reversed its EMT behavior by reducing membrane expression of epithelial markers E-cadherin and $\beta$-catenin in cervical CN2 cells $(152,159)$.

Recent studies have shown more diverse, non-mitotic functions of Aurora-A orchestrating remodeling of the microtubular cytoskeleton during neurite extension (160) but also regulating protrusion and resorption of cellular cilia participating in cellular calcium signaling $(161,162)$. Aurora was shown to localize at the basal body of the cilium and its activation was shown to participate to the ciliary resorption by promoting histone deacetylase-dependent tubulin depolymerization of the ciliary axoneme (161).

The serum growth factors were also shown to induce Aurora-A activation at the basal body of the cell cilium in non-cycling G0/G1 cells causing Aurora-A and NEDD9-dependent cilia resorption (161).HEF1/Cas-L/NEDD9 is a component of focal adhesions that has a prominent role in inducing metastasis and that co-localizes with Aurora-A at the centrosome, thereby enhancing the effect of Aurora-A on the resorption of the cilium. After cilia resorption, Aurora-A ceases to be active (as judged by kinase activity) and will probably be reactivated for mitotic function as soon as the cell enters the cell cycle. By microinjecting active Aurora-A into cells, the cilium disappeared, leading to the conclusion that active Aurora-A is necessary and sufficient to induce cilium resorption (163). Loss of cilia associated with high level Aurora-A expression would indirectly impact the functionality of the cilia-dependent and cancer-relevant signaling cascades, such as those involving Hedgehog (164).

Pathological conditions of the kidney include renal cell carcinoma, in which elevated Aurora-A expression has (often) been reported (165) as well as its partner $\operatorname{NEDD} 9(72,166,167)$. Aurora-A pathway is induced through HIF (hypoxia-inducible factor-1) in ccRCC cells and has significant impact on two relevant features of $V H L$-defective cells: the suppression of primary cilia that in vivo can lead to premalignant cysts and the increased motility that can lead to metastasis (168). However, the underlying mechanism by which VHL loss increases Aurora-A levels has not been clearly elucidated, although it has been suggested that HIF- $1 \alpha$ mediates increased Aurora-A expression in VHL-null cells. Dere et al suggested that Aurora-A expression 

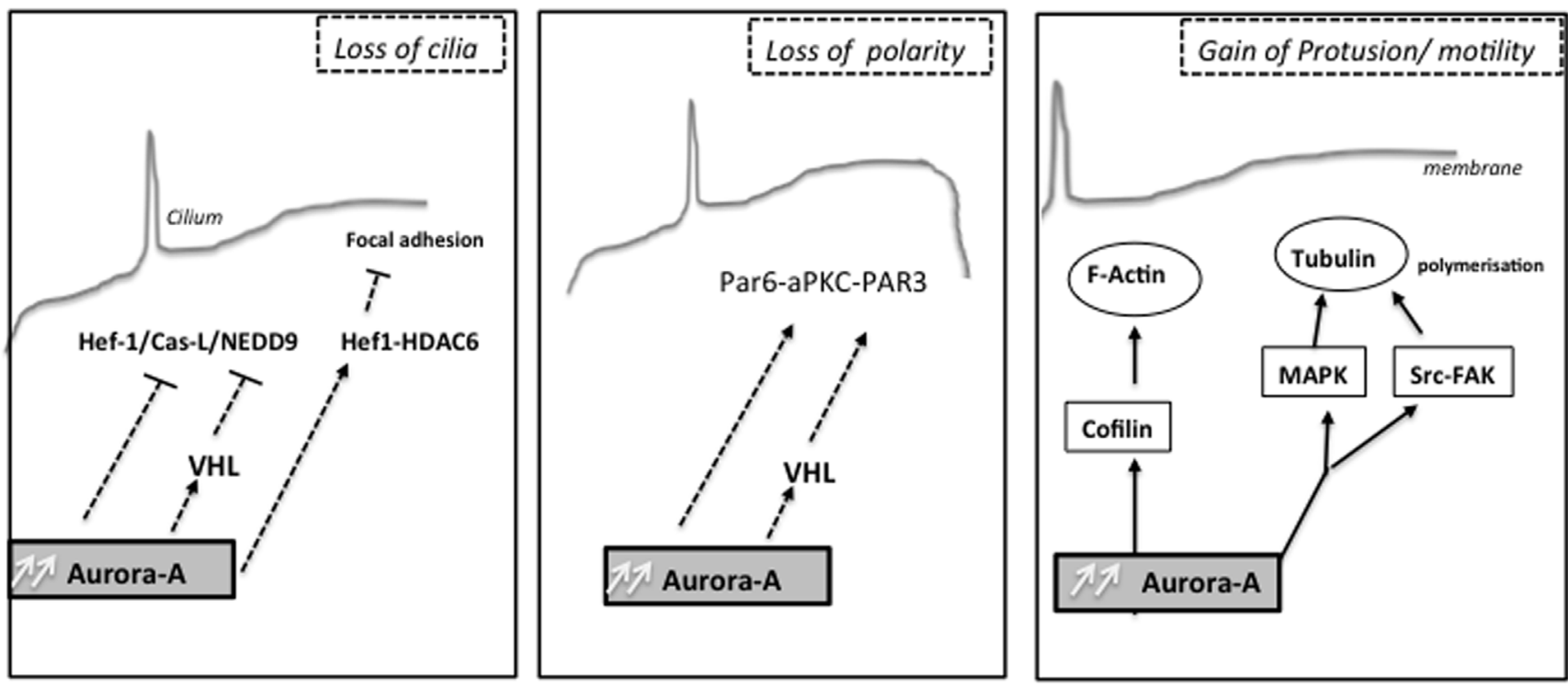

FIGURE 2 | Non-mitotic functions of the kinase Aurora-A: different biological processes as cilia resorption, cell polarity or cell migration are influenced by Aurora-A upstream mitosis, which can later affect chromosome segregation.

is driven by $\beta$-catenin transcription in the VHL null cells and that the level of Aurora-A was not modified by Hif1- $\alpha$ (169).

Clear cell renal cell carcinoma is also characterized by VHL inactivation and more recent data indicate that VHL interacts with primary cilia in renal epithelial cells. A hallmark of ccRCC is loss of the primary cilium. Loss of this key organelle in ccRCC is caused by loss of VHL and associated with increased Aurora-A and histone deacetylase 6 (HDAC6) activities, which drive disassembly of the primary cilium. Aurora-A is typically described as solely localized to the centrosome or centrosomally derived ciliary basal body and otherwise hard to detect in non-cycling normal mammalian cells. Evidence that HEF1/Aurora-A/ HDAC6 signaling axis governs the resorption of cilia in addition to the previously defined roles for these proteins suggests a novel molecular mechanism to explain some cancer-associated ciliary loss. The focal adhesion protein HEF1 initially interacts with Aurora-A in G2 prior to the kinase activation. As the cell progresses throughout the cell cycle, focal adhesion disassembly releases a pool of HEF1, which promotes Aurora-A activation. Overexpression of HEF1 and Aurora-A promotes cytokinetic failure, and contributes to genomic instability. The protein association may interfere with a normal cellular interconversion between cilia and centrosome and contributes to cell cycle by staging critical signaling complexes that govern emergence from quiescence to $\mathrm{S}$ phase, and initiation of $\mathrm{M}$ phase.

Interestingly, formation of renal cysts is very strongly linked to defects in planar cell polarity control $(170,171)$. Aurora-A has also been found to directly phosphorylate Par-6, which together with atypical PKC and Par-3 regulate asymmetric cell division and cell polarity (172) and the changes in $\mathrm{Ca}^{2+}$ signaling induced by autosomal-dominant PKD (ADPKD)-associated mutations in the PKD1 and PKD2 genes (173-175). Low concentrations of drugs that inhibit Aurora-A activity raise basal intracellular $\mathrm{Ca}^{2+}$ levels in renal cells and PC2-dependent $\mathrm{Ca}^{2+}$ release. It has been also demonstrated that Aurora-A directly binds and phosphorylates PC2, and consequently may provide a mechanism by which Aurora-A inhibition limits $\mathrm{PC} 2 \mathrm{Ca}^{2+}$ channel activity. Moreover, the release of $\mathrm{Ca}^{2+}$ from the ER to the cytoplasm transiently activated Aurora-A, based on induced direct $\mathrm{Ca}^{2+}$-calmodulin (CaM) binding to Aurora-A. The non-mitotic activities of Aurora-A likely contribute to deregulation of growth in tumor cells overexpressing Aurora-A (Figure 2).

\section{CONCLUSION}

Clear cell renal cell carcinoma is the predominant type of kidney cancer. ccRCC develops in the renal proximal tube and is linked to biallelic inactivation of the VHL tumor suppressor gene. Mitotic kinases defects mostly lead to aneuploid tumors and the sustained overexpression and activity of various mitotic kinases, including Aurora-A, Polo-like (Plk1), CK2, DCLK in diverse human tumors strongly indicate that these entities are intimately involved in the development of errors in chromosome segregation. Nevertheless, the non-mitotic functions of these kinases involved in the process of ciliogenesis, hypoxia, the EMT as well as the cell polarity likely play an important role in the process of tumorigenesis in kidney cancer as they also lead to genetic instability.

\section{ACKNOWLEDGMENTS}

We would like to acknowledge the SFR Biosit CNRS UMS3480, the Bretagne Region, the INCA, and the LNCC for supporting the team projects. 


\section{REFERENCES}

1. Malumbres M, Barbacid M. Cell cycle kinases in cancer. Curr Opin Genet Dev (2007) 17:60-5. doi:10.1016/j.gde.2006.12.008

2. Li JJ, Li SA. Mitotic kinases: the key to duplication, segregation, and cytokinesis errors, chromosomal instability, and oncogenesis. Pharmacol Ther (2006) 111:974-84. doi:10.1016/j.pharmthera.2006.02.006

3. Lapenna S, Giordano A. Cell cycle kinases as therapeutic targets for cancer. Nat Rev Drug Discov (2009) 8:547-66. doi:10.1038/nrd2907

4. Ellenbroek SI, Iden S, Collard JG. Cell polarity proteins and cancer. Semin Cancer Biol (2012) 22:208-15. doi:10.1016/j.semcancer.2012.02.012

5. Feigin ME, Muthuswamy SK. Polarity proteins regulate mammalian cell-cell junctions and cancer pathogenesis. Curr Opin Cell Biol (2009) 21:694-700. doi:10.1016/j.ceb.2009.07.003

6. Li P, Mao X, Ren Y, Liu P. Epithelial cell polarity determinant CRB3 in cancer development. Int J Biol Sci (2015) 11:31-7. doi:10.7150/ijbs.10615

7. Halaoui R, McCaffrey L. Rewiring cell polarity signaling in cancer. Oncogene (2015) 34:939-50. doi:10.1038/onc.2014.59

8. Rodriguez-Boulan E, Macara IG. Organization and execution of the epithelial polarity programme. Nat Rev Mol Cell Biol (2014) 15:225-42. doi:10.1038/ nrm 3775

9. Schluter MA, Margolis B. Apicobasal polarity in the kidney. Exp Cell Res (2012) 318:1033-9. doi:10.1016/j.yexcr.2012.02.028

10. Lee DB, HuangE, Ward HJ. Tight junction biology and kidney dysfunction. Am J Physiol Renal Physiol (2006) 290:F20-34. doi:10.1152/ajprenal.00052.2005

11. Wilson PD. Apico-basal polarity in polycystic kidney disease epithelia. Biochim Biophys Acta (2011) 1812:1239-48. doi:10.1016/j.bbadis.2011.05.008

12. Godde NJ, Pearson HB, Smith LK, Humbert PO. Dissecting the role of polarity regulators in cancer through the use of mouse models. Exp Cell Res (2014) 328:249-57. doi:10.1016/j.yexcr.2014.08.036

13. Zen K, Yasui K, Gen Y, Dohi O, Wakabayashi N, Mitsufuji S, et al. Defective expression of polarity protein PAR-3 gene (PARD3) in esophageal squamous cell carcinoma. Oncogene (2009) 28:2910-8. doi:10.1038/onc.2009.148

14. Xue B, Krishnamurthy K, Allred DC, Muthuswamy SK. Loss of Par3 promotes breast cancer metastasis by compromising cell-cell cohesion. Nat Cell Biol (2013) 15:189-200. doi:10.1038/ncb2663

15. McCaffrey LM, Montalbano J, Mihai C, Macara IG. Loss of the Par3 polarity protein promotes breast tumorigenesis and metastasis. Cancer Cell (2012) 22:601-14. doi:10.1016/j.ccr.2012.10.003

16. Rothenberg SM, Mohapatra G, Rivera MN, Winokur D, Greninger P, Nitta M, et al. A genome-wide screen for microdeletions reveals disruption of polarity complex genes in diverse human cancers. Cancer Res (2010) 70:2158-64. doi:10.1158/0008-5472.CAN-09-3458

17. Dugay F, Le Goff X, Rioux-Leclerq N, Chesnel F, Jouan F, Henry C, et al. Overexpression of the polarity protein PAR-3 in clear cell renal cell carcinoma is associated with poor prognosis. Int J Cancer (2014) 134:2051-60. doi:10.1002/ijc. 28548

18. Jan YJ, Ko BS, Liu TA, Wu YM, Liang SM, Chen SC, et al. Expression of partitioning defective 3 (par-3) for predicting extrahepatic metastasis and survival with hepatocellular carcinoma. Int J Mol Sci (2013) 14:1684-97. doi:10.3390/ijms14011684

19. Iden S, van Riel WE, Schäfer R, Song JY, Hirose T, Ohno S, et al. Tumor type-dependent function of the par3 polarity protein in skin tumorigenesis. Cancer Cell (2012) 22:389-403. doi:10.1016/j.ccr.2012.08.004

20. Paraf F, Chauveau D, Chrétien Y, Richard S, Grünfeld JP, Droz D. Renal lesions in von Hippel-Lindau disease: immunohistochemical expression of nephron differentiation molecules, adhesion molecules and apoptosis proteins. Histopathology (2000) 36:457-65. doi:10.1046/j.1365-2559.2000.00857.x

21. Kuehn A, Paner GP, Skinnider BF, Cohen C, Datta MW, Young AN, et al. Expression analysis of kidney-specific cadherin in a wide spectrum of traditional and newly recognized renal epithelial neoplasms: diagnostic and histogenetic implications. Am J Surg Pathol (2007) 31:1528-33. doi:10.1097/ PAS.0b013e318058818c

22. Davis CF, Ricketts CJ, Wang M, Yang L, Cherniack AD, Shen H, et al. The somatic genomic landscape of chromophobe renal cell carcinoma. Cancer Cell (2014) 26:319-30. doi:10.1016/j.ccr.2014.07.014

23. Frew IJ, Moch H. A clearer view of the molecular complexity of clear cell renal cell carcinoma. Annu Rev Pathol (2015) 10:263-89. doi:10.1146/ annurev-pathol-012414-040306
24. Cavatorta AL, Fumero G, Chouhy D, Aguirre R, Nocito AL, Giri AA, et al. Differential expression of the human homologue of Drosophila discs large oncosuppressor in histologic samples from human papillomavirus-associated lesions as a marker for progression to malignancy. Int J Cancer (2004) 111:373-80. doi:10.1002/ijc.20275

25. Dagher J, Dugay F, Rioux-Leclercq N, Verhoest G, Oger E, Bensalah K, et al. Cytoplasmic PAR-3 protein expression is associated with adverse prognostic factors in clear cell renal cell carcinoma and independently impacts survival. Hum Pathol (2014) 45:1639-46. doi:10.1016/j. humpath.2014.03.018

26. Karp CM, Tan TT, Mathew R, Nelson D, Mukherjee C, Degenhardt K, et al. Role of the polarity determinant crumbs in suppressing mammalian epithelial tumor progression. Cancer Res (2008) 68:4105-15. doi:10.1158/0008-5472. CAN-07-6814

27. Rehder D, Iden S, Nasdala I, Wegener J, Brickwedde MK, Vestweber D, et al. Junctional adhesion molecule-a participates in the formation of apico-basal polarity through different domains. Exp Cell Res (2006) 312:3389-403. doi:10.1016/j.yexcr.2006.07.004

28. Mao X, Li P, Ren Y, Li J, Zhou C, Yang J, et al. Cell polarity protein CRB3 is an independent favorable prognostic factor for clear cell renal cell carcinoma. Int J Oncol (2015) 46:657-66. doi:10.3892/ijo.2014.2763

29. Kalluri R, Weinberg RA. The basics of epithelial-mesenchymal transition. $J$ Clin Invest (2009) 119:1420-8. doi:10.1172/JCI39104

30. Chen D, Gassenmaier M, Maruschke M, Riesenberg R, Pohla H, Stief CG, et al. Expression and prognostic significance of a comprehensive epithelial-mesenchymal transition gene set in renal cell carcinoma. J Urol (2014) 191:479-86. doi:10.1016/j.juro.2013.08.052

31. Harada K, Miyake H, Kusuda Y, Fujisawa M. Expression of epithelial-mesenchymal transition markers in renal cell carcinoma: impact on prognostic outcomes in patients undergoing radical nephrectomy. BJU Int (2012) 110:E1131-7. doi:10.1111/j.1464-410X.2012.11297.x

32. Fang Y, Wei J, Cao J, Zhao H, Liao B, Qiu S, et al. Protein expression of ZEB2 in renal cell carcinoma and its prognostic significance in patient survival. PLoS One (2013) 8:e62558. doi:10.1371/journal.pone.0062558

33. Mikami S, Oya M, Mizuno R, Kosaka T, Katsube K, Okada Y. Invasion and metastasis of renal cell carcinoma. Med Mol Morphol (2014) 47:63-7. doi:10.1007/s00795-013-0064-6

34. O'Mahony FC, Faratian D, Varley J, Nanda J, Theodoulou M, Riddick AC, et al. The use of automated quantitative analysis to evaluate epithelial-to-mesenchymal transition associated proteins in clear cell renal cell carcinoma. PLoS One (2012) 7:e31557. doi:10.1371/journal.pone.0031557

35. Ni D, Ma X, Li HZ, Gao Y, Li XT, Zhang Y, et al. Downregulation of FOXO3a promotes tumor metastasis and is associated with metastasis-free survival of patients with clear cell renal cell carcinoma. Clin Cancer Res (2014) 20:1779-90. doi:10.1158/1078-0432.CCR-13-1687

36. Morais C, Johnson DW, Vesey DA, Gobe GC. Functional significance of erythropoietin in renal cell carcinoma. BMC Cancer (2013) 13:14. doi:10.1186/1471-2407-13-14

37. Dos Santos C, Tijeras-Raballand A, Serova M, Sebbagh S, Slimane K, Faivre S, et al. Effects of preset sequential administrations of sunitinib and everolimus on tumour differentiation in Caki-1 renal cell carcinoma. Br J Cancer (2015) 112:86-94. doi:10.1038/bjc.2014.578

38. Chuang MJ, Sun KH, Tang SJ, Deng MW, Wu YH, Sung JS, et al. Tumorderived tumor necrosis factor-alpha promotes progression and epithelial-mesenchymal transition in renal cell carcinoma cells. Cancer Sci (2008) 99:905-13. doi:10.1111/j.1349-7006.2008.00756.x

39. Ho MY, Tang SJ, Chuang MJ, Cha TL, Li JY, Sun GH, et al. TNF-alpha induces epithelial-mesenchymal transition of renal cell carcinoma cells via a GSK3beta-dependent mechanism. Mol Cancer Res (2012) 10:1109-19. doi:10.1158/1541-7786.MCR-12-0160

40. Wu ST, Sun GH, Hsu CY, Huang CS, Wu YH, Wang HH, et al. Tumor necrosis factor-alpha induces epithelial-mesenchymal transition of renal cell carcinoma cells via a nuclear factor kappa B-independent mechanism. Exp Biol Med (Maywood) (2011) 236:1022-9. doi:10.1258/ebm.2011.011058

41. Khawam K, Giron-Michel J, Gu Y, Perier A, Giuliani M, Caignard A, et al. Human renal cancer cells express a novel membrane-bound interleukin-15 that induces, in response to the soluble interleukin-15 receptor alpha chain, epithelial-to-mesenchymal transition. Cancer Res (2009) 69:1561-9. doi:10.1158/0008-5472.CAN-08-3198 
42. Giron-Michel J, Azzi S, Khawam K, Caignard A, Devocelle A, Perrier A, et al. Interleukin-15 is a major regulator of the cell-microenvironment interactions in human renal cancer. Bull Cancer (2011) 98:32-9. doi:10.1684/ bdc.2011.1359

43. Span PN, Bussink J. Biology of hypoxia. Semin Nucl Med (2015) 45:101-9. doi:10.1053/j.semnuclmed.2014.10.002

44. Jain RK. Normalizing tumor microenvironment to treat cancer: bench to bedside to biomarkers. J Clin Oncol (2013) 31:2205-18. doi:10.1200/ JCO.2012.46.3653

45. De Bock K, Cauwenberghs S, Carmeliet P. Vessel abnormalization: another hallmark of cancer? Molecular mechanisms and therapeutic implications. Curr Opin Genet Dev (2011) 21:73-9. doi:10.1016/j.gde.2010.10.008

46. Padera TP, Stoll BR, Tooredman JB, Capen D, di Tomaso E, Jain RK. Pathology: cancer cells compress intratumour vessels. Nature (2004) 427:695. doi:10.1038/427695a

47. Sato Y, Yoshizato T, Shiraishi Y, Maekawa S, Okuno Y, Kamura T, et al. Integrated molecular analysis of clear-cell renal cell carcinoma. Nat Genet (2013) 45:860-7. doi:10.1038/ng.2699

48. Yu F, White SB, Zhao Q, Lee FS. HIF-1alpha binding to VHL is regulated by stimulus-sensitive proline hydroxylation. Proc Natl Acad Sci U S A (2001) 98:9630-5. doi:10.1073/pnas.181341498

49. Ivan M, Kondo K, Yang H, Kim W, Valiando J, Ohh M, et al. HIFalpha targeted for VHL-mediated destruction by proline hydroxylation: implications for O2 sensing. Science (2001) 292:464-8. doi:10.1126/ science. 1059817

50. Cockman ME, Masson N, Mole DR, Jaakkola P, Chang GW, Clifford SC, et al. Hypoxia inducible factor-alpha binding and ubiquitylation by the von Hippel-Lindau tumor suppressor protein. J Biol Chem (2000) 275:25733-41. doi:10.1074/jbc.M002740200

51. Tomisawa M, Tokunaga T, Oshika Y, Tsuchida T, Fukushima Y, Sato H, et al. Expression pattern of vascular endothelial growth factor isoform is closely correlated with tumour stage and vascularisation in renal cell carcinoma. Eur J Cancer (1999) 35:133-7. doi:10.1016/S0959-8049(98)00278-0

52. Igarashi H, Esumi M, Ishida H, Okada K. Vascular endothelial growth factor overexpression is correlated with von Hippel-Lindau tumor suppressor gene inactivation in patients with sporadic renal cell carcinoma. Cancer (2002) 95:47-53. doi:10.1002/cncr.10635

53. Escudier B, Eisen T, Stadler WM, Szczylik C, Oudard S, Siebels M, et al. Sorafenib in advanced clear-cell renal-cell carcinoma. N Engl J Med (2007) 356:125-34. doi:10.1056/NEJMoa060655

54. Motzer RJ, Michaelson MD, Redman BG, Hudes GR, Wilding G, Figlin RA, et al. Activity of SU11248, a multitargeted inhibitor of vascular endothelial growth factor receptor and platelet-derived growth factor receptor, in patients with metastatic renal cell carcinoma. J Clin Oncol (2006) 24:16-24. doi:10.1200/JCO.2005.02.2574

55. Sternberg CN, Davis ID, Mardiak J, Szczylik C, Lee E, Wagstaff J, et al. Pazopanib in locally advanced or metastatic renal cell carcinoma: results of a randomized phase III trial. J Clin Oncol (2010) 28:1061-8. doi:10.1200/ JCO.2009.23.9764

56. Land SC, Tee AR. Hypoxia-inducible factor lalpha is regulated by the mammalian target of rapamycin (mTOR) via an mTOR signaling motif. $J$ Biol Chem (2007) 282:20534-43. doi:10.1074/jbc.M611782200

57. Keith B, Johnson RS, Simon MC. HIF1alpha and HIF2alpha: sibling rivalry in hypoxic tumour growth and progression. Nat Rev Cancer (2012) 12:9-22. doi: $10.1038 / \mathrm{nrc} 3183$

58. Shen C, Kaelin WG Jr. The VHL/HIF axis in clear cell renal carcinoma. Semin Cancer Biol (2013) 23:18-25. doi:10.1016/j.semcancer.2012.06.001

59. Latta H, Maunsbach AB, Madden SC. Cilia in different segments of the rat nephron. J Biophys Biochem Cytol (1961) 11:248-52. doi:10.1083/jcb.11.1.248

60. Praetorius HA, Spring KR. Bending the MDCK cell primary cilium increases intracellular calcium. J Membr Biol (2001) 184:71-9. doi:10.1007/ s00232-001-0075-4

61. Yamaguchi T, Nagao S, Wallace DP, Belibi FA, Cowley BD, Pelling JC, et al. Cyclic AMP activates B-Raf and ERK in cyst epithelial cells from autosomal-dominant polycystic kidneys. Kidney Int (2003) 63:1983-94. doi:10.1046/j.1523-1755.2003.00023.x

62. Calvet JP. Strategies to inhibit cyst formation in ADPKD. Clin J Am Soc Nephrol (2008) 3:1205-11. doi:10.2215/CJN.05651207
63. Alenghat FJ, Nauli SM, Kolb R, Zhou J, Ingber DE. Global cytoskeletal control of mechanotransduction in kidney epithelial cells. Exp Cell Res (2004) 301:23-30. doi:10.1016/j.yexcr.2004.08.003

64. Zhang Q, Taulman PD, Yoder BK. Cystic kidney diseases: all roads lead to the cilium. Physiology (Bethesda) (2004) 19:225-30. doi:10.1152/ physiol.00003.2004

65. Nauli SM, Alenghat FJ, Luo Y, Williams E, Vassilev P, Li X, et al. Polycystins 1 and 2 mediate mechanosensation in the primary cilium of kidney cells. Nat Genet (2003) 33:129-37. doi:10.1038/ng1076

66. Quarmby LM, Parker JD. Cilia and the cell cycle? JCell Biol (2005) 169:707-10. doi:10.1083/jcb.200503053

67. Yoder BK. Role of primary cilia in the pathogenesis of polycystic kidney disease. J Am Soc Nephrol (2007) 18:1381-8. doi:10.1681/ASN.2006111215

68. Veland IR, Awan A, Pedersen LB, Yoder BK, Christensen ST. Primary cilia and signaling pathways in mammalian development, health and disease. Nephron Physiol (2009) 111:39-53. doi:10.1159/000208212

69. Schermer B, Ghenoiu C, Bartram M, Müller RU, Kotsis F, Höhne M, et al. The von Hippel-Lindau tumor suppressor protein controls ciliogenesis by orienting microtubule growth. J Cell Biol (2006) 175:547-54. doi:10.1083/ jcb.200605092

70. Fan S, Hurd TW, Liu CJ, Straight SW, Weimbs T, Hurd EA, et al. Polarity proteins control ciliogenesis via kinesin motor interactions. Curr Biol (2004) 14:1451-61. doi:10.1016/j.cub.2004.08.025

71. Lolkema MP, Mans DA, Snijckers CM, van Noort M, van Beest M, Voest EE, et al. The von Hippel-Lindau tumour suppressor interacts with microtubules through kinesin-2. FEBS Lett (2007) 581:4571-6. doi:10.1016/j. febslet.2007.08.050

72. Pugacheva EN, Golemis EA. The focal adhesion scaffolding protein HEF1 regulates activation of the Aurora-A and Nek2 kinases at the centrosome. Nat Cell Biol (2005) 7:937-46. doi:10.1038/ncb1309

73. Kops GJ, Weaver BA, Cleveland DW. On the road to cancer: aneuploidy and the mitotic checkpoint. Nat Rev Cancer (2005) 5:773-85. doi:10.1038/ nrc1714

74. Carter SL, Eklund AC, Kohane IS, Harris LN, Szallasi Z. A signature of chromosomal instability inferred from gene expression profiles predicts clinical outcome in multiple human cancers. Nat Genet (2006) 38:1043-8. doi:10.1038/ng1861

75. McGranahan N, Burrell RA, Endesfelder D, Novelli MR, Swanton C. Cancer chromosomal instability: therapeutic and diagnostic challenges. EMBO Rep (2012) 13:528-38. doi:10.1038/embor.2012.61

76. Musacchio A, Salmon ED. The spindle-assembly checkpoint in space and time. Nat Rev Mol Cell Biol (2007) 8:379-93. doi:10.1038/nrm2163

77. Malumbres M, Barbacid M. Cell cycle, CDKs and cancer: a changing paradigm. Nat Rev Cancer (2009) 9:153-66. doi:10.1038/nrc2602

78. Lipp JJ, Hirota T, Poser I, Peters JM. Aurora B controls the association of condensin I but not condensin II with mitotic chromosomes. J Cell Sci (2007) 120:1245-55. doi: $10.1242 /$ jcs. 03425

79. Tada K, Susumu H, Sakuno T, Watanabe Y. Condensin association with histone H2A shapes mitotic chromosomes. Nature (2011) 474:477-83. doi:10.1038/nature10179

80. Kitagawa M, Lee SH. The chromosomal passenger complex (CPC) as a key orchestrator of orderly mitotic exit and cytokinesis. Front Cell Dev Biol (2015) 3:14. doi:10.3389/fcell.2015.00014

81. Perez de Castro I, de Carcer G, Malumbres M. A census of mitotic cancer genes: new insights into tumor cell biology and cancer therapy. Carcinogenesis (2007) 28:899-912. doi:10.1093/carcin/bgm019

82. Fukasawa K. Oncogenes and tumour suppressors take on centrosomes. Nat Rev Cancer (2007) 7:911-24. doi:10.1038/nrc2249

83. Torres EM, Sokolsky T, Tucker CM, Chan LY, Boselli M, Dunham MJ, et al. Effects of aneuploidy on cellular physiology and cell division in haploid yeast. Science (2007) 317:916-24. doi:10.1126/science.1142210

84. Hell MP, Thoma CR, Fankhauser N, Christinat Y, Weber TC, Krek W. miR-28-5p promotes chromosomal instability in VHL-associated cancers by inhibiting Mad2 translation. Cancer Res (2014) 74:2432-43. doi:10.1158/0008-5472.CAN-13-2041

85. Thoma CR, Toso A, Gutbrodt KL, Reggi SP, Frew IJ, Schraml P, et al. VHL loss causes spindle misorientation and chromosome instability. Nat Cell Biol (2009) 11:994-1001. doi:10.1038/ncb1912 
86. Hell MP, Duda M, Weber TC, Moch H, Krek W. Tumor suppressor VHL functions in the control of mitotic fidelity. Cancer Res (2014) 74:2422-31. doi:10.1158/0008-5472.CAN-13-2040

87. Wilting SM, Snijders PJ, Verlaat W, Jaspers A, van de Wiel MA, van Wieringen $\mathrm{WN}$, et al. Altered microRNA expression associated with chromosomal changes contributes to cervical carcinogenesis. Oncogene (2013) 32:106-16. doi:10.1038/onc.2012.20

88. Albers J, Rajski M, Schönenberger D, Harlander S, Schraml P, von Teichman A, et al. Combined mutation of Vhl and Trp53 causes renal cysts and tumours in mice. EMBO Mol Med (2013) 5:949-64. doi:10.1002/emmm.201202231

89. de Carcer G, Manning G, Malumbres M. From Plk1 to Plk5: functional evolution of polo-like kinases. Cell Cycle (2011) 10:2255-62. doi:10.4161/ cc.10.14.16494

90. Petronczki M, Lenart P, Peters JM. Polo on the rise-from mitotic entry to cytokinesis with Plk1. Dev Cell (2008) 14:646-59. doi:10.1016/j. devcel.2008.04.014

91. Archambault V, Glover DM. Polo-like kinases: conservation and divergence in their functions and regulation. Nat Rev Mol Cell Biol (2009) 10:265-75. doi:10.1038/nrm2653

92. Zitouni S, Nabais C, Jana SC, Guerrero A, Bettencourt-Dias M. Polo-like kinases: structural variations lead to multiple functions. Nat Rev Mol Cell Biol (2014) 15:433-52. doi:10.1038/nrm3819

93. Strebhardt K. Multifaceted polo-like kinases: drug targets and antitargets for cancer therapy. Nat Rev Drug Discov (2010) 9:643-60. doi:10.1038/nrd3184

94. Schöffski P, Blay JY, De Greve J, Brain E, Machiels JP, Soria JC, et al. Multicentric parallel phase II trial of the polo-like kinase 1 inhibitor BI 2536 in patients with advanced head and neck cancer, breast cancer, ovarian cancer, soft tissue sarcoma and melanoma. The first protocol of the European Organization for Research and Treatment of Cancer (EORTC) Network of Core Institutes (NOCI). Eur J Cancer (2010) 46:2206-15. doi:10.1016/j. ejca.2010.03.039

95. Zhao C, Gong L, Li W, Chen L. Overexpression of Plk1 promotes malignant progress in human esophageal squamous cell carcinoma. J Cancer Res Clin Oncol (2010) 136:9-16. doi:10.1007/s00432-009-0630-4

96. He ZL, Zheng H, Lin H, Miao XY, Zhong DW. Overexpression of polo-like kinase1 predicts a poor prognosis in hepatocellular carcinoma patients. World J Gastroenterol (2009) 15:4177-82. doi:10.3748/wjg.15.4177

97. Zhang Z, Zhang G, Kong C. High expression of polo-like kinase 1 is associated with the metastasis and recurrence in urothelial carcinoma of bladder. Urol Oncol (2013) 31:1222-30. doi:10.1016/j.urolonc.2011.11.028

98. Salvatore G, Nappi TC, Salerno P, Jiang Y, Garbi C, Ugolini C, et al. A cell proliferation and chromosomal instability signature in anaplastic thyroid carcinoma. Cancer Res (2007) 67:10148-58. doi:10.1158/0008-5472. CAN-07-1887

99. Ito Y, Miyoshi E, Sasaki N, Kakudo K, Yoshida H, Tomoda C, et al. Pololike kinase 1 overexpression is an early event in the progression of papillary carcinoma. Br J Cancer (2004) 90:414-8. doi:10.1038/sj.bjc.6601540

100. Takahashi T, Sano B, Nagata T, Kato H, Sugiyama Y, Kunieda K, et al. Pololike kinase 1 (PLK1) is overexpressed in primary colorectal cancers. Cancer Sci (2003) 94:148-52. doi:10.1111/j.1349-7006.2003.tb01411.x

101. Gray PJ Jr, Bearss DJ, Han H, Nagle R, Tsao MS, Dean N, et al. Identification of human polo-like kinase 1 as a potential therapeutic target in pancreatic cancer. Mol Cancer Ther (2004) 3:641-6.

102. Weichert W, Schmidt M, Gekeler V, Denkert C, Stephan C, Jung K, et al. Polo-like kinase 1 is overexpressed in prostate cancer and linked to higher tumor grades. Prostate (2004) 60:240-5. doi:10.1002/pros.20050

103. Kneisel L, Strebhardt K, Bernd A, Wolter M, Binder A, Kaufmann R. Expression of polo-likekinase (PLK1) in thin melanomas: a novel marker of metastatic disease. J Cutan Pathol (2002) 29:354-8. doi:10.1034/j.1600-0560.2002.290605.x

104. Maire V, Némati F, Richardson M, Vincent-Salomon A, Tesson B, Rigaill G, et al. Polo-like kinase 1: a potential therapeutic option in combination with conventional chemotherapy for the management of patients with triple-negative breast cancer. Cancer Res (2013) 73:813-23. doi:10.1158/0008-5472. CAN-12-2633

105. Weichert W, Denkert C, Schmidt M, Gekeler V, Wolf G, Köbel M, et al. Pololike kinase isoform expression is a prognostic factor in ovarian carcinoma. $\mathrm{Br}$ J Cancer (2004) 90:815-21. doi:10.1038/sj.bjc.6601610

106. Ding Y, Huang D, Zhang Z, Smith J, Petillo D, Looyenga BD, et al. Combined gene expression profiling and RNAi screening in clear cell renal cell carcinoma identify PLK1 and other therapeutic kinase targets. Cancer Res (2011) 71:5225-34. doi:10.1158/0008-5472.CAN-11-0076

107. Zhang G, Zhang Z, Liu Z. Polo-like kinase 1 is overexpressed in renal cancer and participates in the proliferation and invasion of renal cancer cells. Tumour Biol (2013) 34:1887-94. doi:10.1007/s13277-013-0732-0

108. Sakurai $Y$, Hatakeyama H, Akita H, Harashima H. Improvement of doxorubicin efficacy using liposomal anti-polo-like kinase 1 siRNA in human renal cell carcinomas. Mol Pharm (2014) 11:2713-9. doi:10.1021/mp500245z

109. Wang G, Chen Q, Zhang X, Zhang B, Zhuo X, Liu J, et al. PCM1 recruits Plk1 to the pericentriolar matrix to promote primary cilia disassembly before mitotic entry. J Cell Sci (2013) 126:1355-65. doi:10.1242/jcs.114918

110. Soung NK, Park JE, Yu LR, Lee KH, Lee JM, Bang JK, et al. Plk1-dependent and -independent roles of an ODF2 splice variant, hCenexin1, at the centrosome of somatic cells. Dev Cell (2009) 16:539-50. doi:10.1016/j. devcel.2009.02.004

111. Lee KH, Johmura Y, Yu LR, Park JE, Gao Y, Bang JK, et al. Identification of a novel Wnt5a-CK1varepsilon-Dvl2-Plk1-mediated primary cilia disassembly pathway. ЕMBO J (2012) 31:3104-17. doi:10.1038/emboj.2012.144

112. Miyamoto T, Hosoba K, Ochiai H, Royba E, Izumi H, Sakuma T, et al. The microtubule-depolymerizing activity of a mitotic kinesin protein KIF2A drives primary cilia disassembly coupled with cell proliferation. Cell Rep (2015) 10:664-73. doi:10.1016/j.celrep.2015.01.003

113. Kobayashi T, Tsang WY, Li J, Lane W, Dynlacht BD. Centriolar kinesin Kif24 interacts with CP110 to remodel microtubules and regulate ciliogenesis. Cell (2011) 145:914-25. doi:10.1016/j.cell.2011.04.028

114. Miyamoto T, Porazinski S, Wang H, Borovina A, Ciruna B, Shimizu A, et al. Insufficiency of BUBR1, a mitotic spindle checkpoint regulator, causes impaired ciliogenesis in vertebrates. Hum Mol Genet (2011) 20:2058-70. doi:10.1093/hmg/ddr090

115. Seeger-Nukpezah T, Liebau MC, Höpker K, Lamkemeyer T, Benzing T, Golemis EA, et al. The centrosomal kinase Plk1 localizes to the transition zone of primary cilia and induces phosphorylation of nephrocystin-1. PLoS One (2012) 7:e38838. doi:10.1371/journal.pone.0038838

116. St-Denis NA, Derksen DR, Litchfield DW. Evidence for regulation of mitotic progression through temporal phosphorylation and dephosphorylation of CK2alpha. Mol Cell Biol (2009) 29:2068-81. doi:10.1128/MCB.01563-08

117. Escargueil AE, Plisov SY, Filhol O, Cochet C, Larsen AK. Mitotic phosphorylation of DNA topoisomerase II alpha by protein kinase CK2 creates the MPM-2 phosphoepitope on Ser-1469. J Biol Chem (2000) 275:34710-8. doi:10.1074/jbc.M005179200

118. Theis-Febvre N, Filhol O, Froment C, Cazales M, Cochet C, Monsarrat B, et al. Protein kinase $\mathrm{CK} 2$ regulates $\mathrm{CDC} 25 \mathrm{~B}$ phosphatase activity. Oncogene (2003) 22:220-32. doi:10.1038/sj.onc.1206107

119. Yde CW, Olsen BB, Meek D, Watanabe N, Guerra B. The regulatory beta-subunit of protein kinase CK2 regulates cell-cycle progression at the onset of mitosis. Oncogene (2008) 27:4986-97. doi:10.1038/onc.2008.146

120. Li H, Liu XS, Yang X, Wang Y, Wang Y, Turner JR, et al. Phosphorylation of CLIP-170 by Plk1 and CK2 promotes timely formation of kinetochore-microtubule attachments. EMBO J (2010) 29:2953-65. doi:10.1038/ emboj.2010.174

121. Peng Y, Wong CC, Nakajima Y, Tyers RG, Sarkeshik AS, Yates J III, et al. Overlapping kinetochore targets of CK2 and Aurora B kinases in mitotic regulation. Mol Biol Cell (2011) 22:2680-9. doi:10.1091/mbc.E10-11-0915

122. Stalter G, Siemer S, Becht E, Ziegler M, Remberger K, Issinger OG. Asymmetric expression of protein kinase CK2 subunits in human kidney tumors. Biochem Biophys Res Commun (1994) 202:141-7. doi:10.1006/ bbrc.1994.1904

123. Siddiqui-Jain A, Drygin D, Streiner N, Chua P, Pierre F, O'Brien SE, et al. CX-4945, an orally bioavailable selective inhibitor of protein kinase CK2, inhibits prosurvival and angiogenic signaling and exhibits antitumor efficacy. Cancer Res (2010) 70:10288-98. doi:10.1158/0008-5472.CAN-10-1893

124. Montenarh M. Protein kinase CK2 and angiogenesis. Adv Clin Exp Med (2014) 23:153-8. doi:10.17219/acem/37040

125. Pluemsampant S, Safronova OS, Nakahama K, Morita I. Protein kinase CK2 is a key activator of histone deacetylase in hypoxia-associated tumors. Int $J$ Cancer (2008) 122:333-41. doi:10.1002/ijc.23094

126. Ampofo E, Kietzmann T, Zimmer A, Jakupovic M, Montenarh M, Götz C. Phosphorylation of the von Hippel-Lindau protein (VHL) by protein kinase CK2 reduces its protein stability and affects p 53 and HIF-1alpha mediated 
transcription. Int J Biochem Cell Biol (2010) 42:1729-35. doi:10.1016/j. biocel.2010.07.008

127. Hubert A, Paris S, Piret JP, Ninane N, Raes M, Michiels C. Casein kinase 2 inhibition decreases hypoxia-inducible factor-1 activity under hypoxia through elevated p53 protein level. J Cell Sci (2006) 119:3351-62. doi:10.1242/ jcs.03069

128. Isaacs JS, Jung YJ, Mimnaugh EG, Martinez A, Cuttitta F, Neckers LM. Hsp90 regulates a von Hippel Lindau-independent hypoxia-inducible factor-1 alpha-degradative pathway. J Biol Chem (2002) 277:29936-44. doi:10.1074/ jbc.M204733200

129. Guerra B, Rasmussen TD, Schnitzler A, Jensen HH, Boldyreff BS, Miyata Y, et al. Protein kinase CK2 inhibition is associated with the destabilization of HIF-1alpha in human cancer cells. Cancer Lett (2015) 356:751-61. doi:10.1016/j.canlet.2014.10.026

130. Kaminska K, Szczylik C, Lian F, Czarnecka AM. The role of prostaglandin E2 in renal cell cancer development: future implications for prognosis and therapy. Future Oncol (2014) 10:2177-87. doi:10.2217/fon.14.152

131. Zou J, Luo H, Zeng Q, Dong Z, Wu D, Liu L. Protein kinase CK2alpha is overexpressed in colorectal cancer and modulates cell proliferation and invasion via regulating EMT-related genes. J Transl Med (2011) 9:97. doi:10.1186/1479-5876-9-97

132. Ku MJ, Park JW, Ryu BJ, Son YJ, Kim SH, Lee SY. CK2 inhibitor CX4945 induces sequential inactivation of proteins in the signaling pathways related with cell migration and suppresses metastasis of A549 human lung cancer cells. Bioorg Med Chem Lett (2013) 23:5609-13. doi:10.1016/j.bmcl.2013.08.043

133. Kim J, Hwan Kim S. CK2 inhibitor CX-4945 blocks TGF-beta1-induced epithelial-to-mesenchymal transition in A549 human lung adenocarcinoma cells. PLoS One (2013) 8:e74342. doi:10.1371/journal.pone.0074342

134. Gönczy P, Bellanger JM, Kirkham M, Pozniakowski A, Baumer K, Phillips JB, et al. zyg-8, a gene required for spindle positioning in C. elegans, encodes a doublecortin-related kinase that promotes microtubule assembly. Dev Cell (2001) 1:363-75. doi:10.1016/S1534-5807(01)00046-6

135. Shu T, Tseng HC, Sapir T, Stern P, Zhou Y, Sanada K, et al. Doublecortin-like kinase controls neurogenesis by regulating mitotic spindles and $\mathrm{M}$ phase progression. Neuron (2006) 49:25-39. doi:10.1016/j.neuron.2005.10.039

136. Nakanishi Y, Seno H, Fukuoka A, Ueo T, Yamaga Y, Maruno T, et al. Dclk1 distinguishes between tumor and normal stem cells in the intestine. Nat Genet (2013) 45:98-103. doi:10.1038/ng.2481

137. Qu D, Johnson J, Chandrakesan P, Weygant N, May R, Aiello N, et al. Doublecortin-like kinase 1 is elevated serologically in pancreatic ductal adenocarcinoma and widely expressed on circulating tumor cells. PLoS One (2015) 10:e0118933. doi:10.1371/journal.pone.0118933

138. Weygant N, Qu D, May R, Tierney RM, Berry WL, Zhao L, et al. DCLK1 is a broadly dysregulated target against epithelial-mesenchymal transition, focal adhesion, and stemness in clear cell renal carcinoma. Oncotarget (2015) 6:2193-205. doi:10.18632/oncotarget.3059

139. Salama MF, Carroll B, Adada M, Pulkoski-Gross M, Hannun YA, Obeid LM. A novel role of sphingosine kinase-1 in the invasion and angiogenesis of VHL mutant clear cell renal cell carcinoma. FASEB J (2015) 29:2803-13. doi:10.1096/fj.15-270413

140. Weygant N, Qu D, Berry WL, May R, Chandrakesan P, Owen DB, et al. Small molecule kinase inhibitor LRRK2-IN-1 demonstrates potent activity against colorectal and pancreatic cancer through inhibition of doublecortin-like kinase 1. Mol Cancer (2014) 13:103. doi:10.1186/1476-4598-13-103

141. Marumoto T, Zhang D, Saya H. Aurora-A - a guardian of poles. Nat Rev Cancer (2005) 5:42-50. doi:10.1038/nrc1526

142. Arlot-Bonnemains Y, Klotzbucher A, Giet R, Uzbekov R, Bihan R, Prigent C. Identification of a functional destruction box in the Xenopus laevis aurora-A kinase pEg2. FEBS Lett (2001) 508:149-52. doi:10.1016/ S0014-5793(01)03048-4

143. Castro A, Arlot-Bonnemains Y, Vigneron S, Labbé JC, Prigent C, Lorca T. APC/Fizzy-Related targets Aurora-A kinase for proteolysis. EMBO Rep (2002) 3:457-62. doi:10.1093/embo-reports/kvf095

144. Hirota T, Kunitoku N, Sasayama T, Marumoto T, Zhang D, Nitta M, et al. Aurora- $A$ and an interacting activator, the LIM protein Ajuba, are required for mitotic commitment in human cells. Cell (2003) 114:585-98. doi:10.1016/ S0092-8674(03)00642-1

145. Satinover DL, Leach CA, Stukenberg PT, Brautigan DL. Activation of Aurora-A kinase by protein phosphatase inhibitor-2, a bifunctional signaling protein. Proc Natl Acad Sci USA (2004) 101:8625-30. doi:10.1073/ pnas.0402966101

146. Hutterer A, Berdnik D, Wirtz-Peitz F, Zigman M, Schleiffer A, Knoblich JA. Mitotic activation of the kinase Aurora-A requires its binding partner Bora. Dev Cell (2006) 11:147-57. doi:10.1016/j.devcel.2006.06.002

147. Shagisultanova E, Dunbrack RL Jr, Golemis EA. Issues in interpreting the in vivo activity of Aurora-A. Expert Opin Ther Targets (2015) 19:187-200. d oi:10.1517/14728222.2014.981154

148. Fu J, Bian M, Jiang Q, Zhang C. Roles of Aurora kinases in mitosis and tumorigenesis. Mol Cancer Res (2007) 5:1-10. doi:10.1158/1541-7786. MCR-06-0208

149. Tanaka E, Hashimoto Y, Ito T, Okumura T, Kan T, Watanabe G, et al. The clinical significance of Aurora-A/STK15/BTAK expression in human esophageal squamous cell carcinoma. Clin Cancer Res (2005) 11:1827-34. doi:10.1158/1078-0432.CCR-04-1627

150. Li D, Zhu J, Firozi PF, Abbruzzese JL, Evans DB, Cleary K, et al. Overexpression of oncogenic STK15/BTAK/Aurora A kinase in human pancreatic cancer. Clin Cancer Res (2003) 9:991-7.

151. Cervigni RI, Barretta ML, Persico A, Corda D, Colanzi A. The role of Aurora-A kinase in the Golgi-dependent control of mitotic entry. Bioarchitecture (2011) 1:61-5. doi:10.4161/bioa.1.2.15329

152. Guan Z, Wang XR, Zhu XF, Huang XF, Xu J, Wang LH, et al. Aurora-A, a negative prognostic marker, increases migration and decreases radiosensitivity in cancer cells. Cancer Res (2007) 67:10436-44. doi:10.1158/0008-5472. CAN-07-1379

153. Wu JC, Chen TY, Yu CT, Tsai SJ, Hsu JM, Tang MJ, et al. Identification of V23RalA-Ser194 as a critical mediator for Aurora-A-induced cellular motility and transformation by small pool expression screening. J Biol Chem (2005) 280:9013-22. doi:10.1074/jbc.M411068200

154. Ganesan R, Mahankali M, Alter G, Gomez-Cambronero J. Two sites of action for PLD2 inhibitors: the enzyme catalytic center and an allosteric, phosphoinositide biding pocket. Biochim Biophys Acta (2015) 1851:261-72. doi:10.1016/j.bbalip.2014.12.007

155. Bailly M, Condeelis J. Cell motility: insights from the backstage. Nat Cell Biol (2002) 4:E292-4. doi:10.1038/ncb1202-e292

156. Ghosh M, Song X, Mouneimne G, Sidani M, Lawrence DS, Condeelis JS. Cofilin promotes actin polymerization and defines the direction of cell motility. Science (2004) 304:743-6. doi:10.1126/science.1094561

157. Wang LH, Xiang J, Yan M, Zhang Y, Zhao Y, Yue CF, et al. The mitotic kinase Aurora-A induces mammary cell migration and breast cancer metastasis by activating the Cofilin-F-actin pathway. Cancer Res (2010) 70:9118-28. doi:10.1158/0008-5472.CAN-10-1246

158. D’Assoro AB, Liu T, Quatraro C, Amato A, Opyrchal M, Leontovich A, et al. The mitotic kinase Aurora - a promotes distant metastases by inducing epithelial-to-mesenchymal transition in ERalpha(+) breast cancer cells. Oncogene (2014) 33:599-610. doi:10.1038/onc.2012.628

159. Wan XB, Long ZJ, Yan M, Xu J, Xia LP, Liu L, et al. Inhibition of Aurora-A suppresses epithelial-mesenchymal transition and invasion by downregulating MAPK in nasopharyngeal carcinoma cells. Carcinogenesis (2008) 29:1930-7. doi:10.1093/carcin/bgn176

160. Mori D, Yamada M, Mimori-Kiyosue Y, Shirai Y, Suzuki A, Ohno S, et al. An essential role of the aPKC-Aurora A-NDEL1 pathway in neurite elongation by modulation of microtubule dynamics. Nat Cell Biol (2009) 11:1057-68. doi:10.1038/ncb1919

161. Pugacheva EN, Jablonski SA, Hartman TR, Henske EP, Golemis EA. HEF1dependent Aurora A activation induces disassembly of the primary cilium. Cell (2007) 129:1351-63. doi:10.1016/j.cell.2007.04.035

162. Plotnikova OV, Pugacheva EN, Golemis EA. Aurora A kinase activity influences calcium signaling in kidney cells. J Cell Biol (2011) 193:1021-32. doi:10.1083/jcb.201012061

163. Plotnikova OV, Golemis EA, Pugacheva EN. Cell cycle-dependent ciliogenesis and cancer. Cancer Res (2008) 68:2058-61. doi:10.1158/0008-5472. CAN-07-5838

164. Wong SY, Seol AD, So PL, Ermilov AN, Bichakjian CK, Epstein EH Jr, et al. Primary cilia can both mediate and suppress Hedgehog pathway-dependent tumorigenesis. Nat Med (2009) 15:1055-61. doi:10.1038/nm.2011

165. Kurahashi T, Miyake H, Hara I, Fujisawa M. Significance of Aurora-A expression in renal cell carcinoma. Urol Oncol (2007) 25:128-33. doi:10.1016/j. urolonc.2006.06.001 
166. Law SF, Estojak J, Wang B, Mysliwiec T, Kruh G, Golemis EA. Human enhancer of filamentation 1, a novel p130cas-like docking protein, associates with focal adhesion kinase and induces pseudohyphal growth in Saccharomyces cerevisiae. Mol Cell Biol (1996) 16:3327-37. doi:10.1128/ MCB.16.7.3327

167. Pugacheva EN, Golemis EA. HEF1-aurora A interactions: points of dialog between the cell cycle and cell attachment signaling networks. Cell Cycle (2006) 5:384-91. doi:10.4161/cc.5.4.2439

168. Xu J, Li H, Wang B, Xu Y, Yang J, Zhang X, et al. VHL inactivation induces HEF1 and Aurora kinase A. J Am Soc Nephrol (2010) 21:2041-6. doi:10.1681/ ASN.2010040345

169. Dere R, Perkins AL, Bawa-Khalfe T, Jonasch D, Walker CL. beta-catenin links von Hippel-Lindau to aurora kinase A and loss of primary cilia in renal cell carcinoma. J Am Soc Nephrol (2015) 26:553-64. doi:10.1681/ ASN.2013090984

170. Fischer E, Legue E, Doyen A, Nato F, Nicolas JF, Torres V, et al. Defective planar cell polarity in polycystic kidney disease. Nat Genet (2006) 38:21-3. doi:10.1038/ng1701

171. Bacallao RL, McNeill H. Cystic kidney diseases and planar cell polarity signaling. Clin Genet (2009) 75:107-17. doi:10.1111/j.1399-0004.2008.01148.x

172. Ogawa H, Ohta N, Moon W, Matsuzaki F. Protein phosphatase 2A negatively regulates aPKC signaling by modulating phosphorylation of Par-6 in
Drosophila neuroblast asymmetric divisions. J Cell Sci (2009) 122:3242-9. doi:10.1242/jcs.050955

173. Hanaoka K, Qian F, Boletta A, Bhunia AK, Piontek K, Tsiokas L, et al. Co-assembly of polycystin-1 and -2 produces unique cation-permeable currents. Nature (2000) 408:990-4. doi:10.1038/35050128

174. Wilson PD. Polycystic kidney disease: new understanding in the pathogenesis. Int J Biochem Cell Biol (2004) 36:1868-73. doi:10.1016/j.biocel.2004.03.012

175. Benzing T, Walz G. Cilium-generated signaling: a cellular GPS? Curr Opin Nephrol Hypertens (2006) 15:245-9. doi:10.1097/01.mnh.0000222690.53970. ca

Conflict of Interest Statement: The authors declare that the research was conducted in the absence of any commercial or financial relationships that could be construed as a potential conflict of interest.

Copyright (c) 2015 Hascoet, Chesnel, Le Goff, Le Goff and Arlot-Bonnemains. This is an open-access article distributed under the terms of the Creative Commons Attribution License (CC BY). The use, distribution or reproduction in other forums is permitted, provided the original author(s) or licensor are credited and that the original publication in this journal is cited, in accordance with accepted academic practice. No use, distribution or reproduction is permitted which does not comply with these terms. 